\title{
Cyclooxygenase-2 utilizes Jun N-terminal kinases to induce invasion, but not tamoxifen resistance, in MCF-7 breast cancer cells
}

\author{
VIANEY GONZALEZ-VILLASANA ${ }^{1,2}$, YOLANDA GUTIÉRREZ-PUENTE ${ }^{1}$ and ANA M. TARI ${ }^{2,3}$ \\ ${ }^{1}$ Department of Biochemistry, Faculty of Biological Sciences, University of Nuevo Leon, San Nicolas de los Garza, \\ Nuevo León, Mexico; ${ }^{2}$ Department of Experimental Therapeutics, University of Texas M.D. Anderson Cancer Center, \\ Houston, TX; ${ }^{3}$ Department of Neuroscience, University of Florida, Gainesville, FL, USA
}

Received April 4, 2013; Accepted May 29, 2013

DOI: 10.3892/or.2013.2549

\begin{abstract}
Elevated cyclooxygenase-2 (COX-2) expression in breast tumors is associated with a lower survival rate in patients with estrogen receptor $\alpha(\mathrm{ER} \alpha)$-positive tumors. We hypothesized that COX-2 reduces the survival rate of breast cancer patients with ER $\alpha$-positive tumors since $\mathrm{COX}-2$ increases the invasiveness of ER $\alpha$-positive breast tumors and decreases tumor sensitivity to tamoxifen. Previously, we demonstrated that $\mathrm{COX}-2$ stimulates the activity of protein kinase $\mathrm{C}(\mathrm{PKC})$ to increase the invasiveness of $\mathrm{ER} \alpha$-positive MCF-7 breast cancer cells and to decrease the sensitivity of MCF-7 cells to tamoxifen. High levels of COX-2 are associated with the activation of the mitogen-activated protein kinase (MAPK) family and the Akt kinase. However, it is not known whether these kinases mediate COX-2-induced invasive activity and tamoxifen resistance. In the present study, we report that COX-2 utilizes PKC to enhance the phosphorylation of Jun N-terminal kinases (JNKs), but not that of other MAPK family members or Akt. Inhibition aimed at JNKs reduced COX-2-induced invasion but not COX-2-induced tamoxifen resistance. We conclude that JNKs are essential for induced cell invasion by COX-2, but not tamoxifen resistance, in ER $\alpha$-positive breast cancer cells.
\end{abstract}

\section{Introduction}

A number of studies have shown high levels of the cyclooxygenase-2 (COX-2) protein in solid tumors (1-6). In breast cancer, COX-2 expression is a predictor of poor disease-free

Correspondence to: Dr Ana M. Tari, Department of Neuroscience, University of Florida, P.O. Box 100244, Gainesville, FL 32611-0244, USA

E-mail: anamtari@ufl.edu

Key words: tamoxifen, breast cancer invasion, cyclooxygenase-2, Jun N-terminal kinases and overall survival (4-9). In a retrospective study of 1,576 invasive breast tumors, Ristimaki et al (4) found that elevated COX-2 expression was associated with a lower survival rate in patients with estrogen receptor $\alpha(\mathrm{ER} \alpha)$-positive breast tumors. Women whose invasive breast tumors were ER $\alpha$-positive but had low levels of COX-2 had an $86 \%$ chance of 5-year distant disease-free survival, whereas women whose tumors were ER $\alpha$-positive but had high levels of COX-2 had a $76 \%$ chance of 5-year distant disease-free survival (4).

Breast cancer patients who have ER $\alpha$-positive breast tumors are typically treated with selective estrogen receptor modulators (SERMs). We previously demonstrated that transfection of the COX-2 gene into the tamoxifen-sensitive, ER $\alpha$-positive MCF-7 breast cancer cell line (MCF-7/COX-2) reduced the sensitivity of MCF-7 cells to tamoxifen by $\sim 5$-fold (10). These data suggest that breast cancer patients who have ER $\alpha$-positive and COX-2-overexpressing tumors may not benefit from tamoxifen as much as patients who have low levels of COX-2 in their ER $\alpha$-positive breast tumors.

Elevated levels of COX-2 have also been associated with lymph node and distant metastasis $(11,12)$. COX-2 has been shown to increase breast cancer cell invasion in vitro (13-15) and in vivo (16-18). We and others demonstrated that MCF-7/COX-2 cells are $\sim 3$-fold more invasive than parental MCF-7 cells $(13,14)$. The decrease in tamoxifen sensitivity and increase in invasive activity by COX-2 may contribute to the reduced survival rate noted in patients with ER $\alpha$-positive, COX-2-overexpressing breast tumors.

COX-2 utilizes its product prostaglandin $\mathrm{E}_{2}\left(\mathrm{PGE}_{2}\right)$ to stimulate protein kinase $\mathrm{C}$ (PKC) activity. We demonstrated that activation of $\mathrm{PKC}$ reduced the anti-proliferative effects of tamoxifen (10), and increased the invasiveness of MCF-7 cells across a Matrigel basement membrane (13). Although high levels of COX-2 have been associated with activation of the mitogen activated protein kinase (MAPK) family (19-21) and the Akt kinase (22), it is not known whether these kinases mediate COX-2-induced tamoxifen resistance and invasive activity. In the present study, we report that COX-2 utilizes PKC to increase the activity of Jun N-terminal kinases (JNKs) to mediate invasion, but not tamoxifen resistance, in MCF-7 breast cancer cells. 


\section{Materials and methods}

Cell lines and culture conditions. The MCF-7 human breast cancer cell line was obtained from the American Type Cell Culture (ATCC, Manassas, VA, USA). MCF-7/COX-2 cells were generated by stably transfecting plasmids encoding the COX-2 gene into ER $\alpha$-positive MCF-7 cells $(10,13)$. MCF-7/COX-2 cells were obtained from individual colonies, and continuously cultured in DMEM/F-12 medium containing $5 \% \mathrm{FBS}$ and $500 \mu \mathrm{g} / \mathrm{ml} \mathrm{G} 418$. We selected clone 12, which expressed higher levels of COX-2 than the parental MCF-7 cells $(10,13)$ for our studies.

Chemical reagents. Tamoxifen citrate, Gö6976, SP600125 and PD98059 were purchased from EMD Chemicals (San Diego, CA, USA). Stock solutions (10 mM) of tamoxifen, Gö6976, SP600125 and PD98059 were prepared in DMSO and stored at $-20^{\circ} \mathrm{C}$. All reagents were diluted in culture medium to the indicated final concentration. Matrigel was purchased from BD Biosciences (Bedford, MA, USA). Antibodies specific for phosphorylated ERK $\left(\mathrm{T}^{202} / \mathrm{Y}^{204}\right)$, phosphorylated p38MAPK $\left(\mathrm{T}^{183} / \mathrm{Y}^{185}\right)$, phosphorylated Akt $\left(\mathrm{S}^{473}\right)$, phosphorylated c-Jun N-terminal kinase (JNK) $\left(\mathrm{T}^{183} / \mathrm{Y}^{185}\right)$, ERK, p38MAPK, Akt, JNK, and c-Jun were obtained from Cell Signaling Technology (Danvers, MA, USA). Antibodies specific for $\beta$-actin and Histone H3 were purchased from Sigma-Aldrich Chemical Co. (St. Louis, MO, USA). Anti-mouse and anti-rabbit secondary antibodies conjugated with horseradish peroxidase were purchased from Amersham Life Sciences (Cell Signaling Technology).

Western blotting. Western blotting was performed as previously described (10,23). MCF-7 parental and MCF-7/ COX-2 cells were plated at $4 \times 10^{5}$ cells/well in 6 -well plates in DMEM/F-12 medium containing 5\% FBS. Two days later, cells were harvested and cell pellets were lysed. The protein concentration was determined using the DC protein assay (Bio-Rad Laboratories, Hercules, CA, USA). Samples were electrophoresed on $12 \%$ polyacrylamide gels (Bio-Rad Laboratories), then transferred to nitrocellulose membranes (Bio-Rad Laboratories) for western blot analysis. Membranes were blocked in Tris-buffered saline $(20 \mathrm{mM}$ Tris $\mathrm{pH} 7.6$, $150 \mathrm{mM} \mathrm{NaCl}$ ) with $0.1 \%$ Tween-20 containing 5\% non-fat dry milk (Bio-Rad Laboratories) at room temperature for $30 \mathrm{~min}$. After washing, the membranes were incubated with primary antibodies (1:1,000 dilution) overnight at $4^{\circ} \mathrm{C}$. The next day, membranes were washed and incubated with anti-rabbit secondary antibody conjugated with horseradish peroxidase (1:1,000 dilution) for $2 \mathrm{~h}$ at room temperature. Proteins bands were detected via enhanced chemiluminescence (Kirkegaard \& Perry Laboratories, Gaithersburg, MD, USA). Images were scanned by an AlphaImager densitometer (Alpha Innotech Corp., San Leandro, CA, USA). $\beta$-actin was used as a loading control. Membranes were incubated with anti- $\beta$-actin antibody (1:10,000 dilution) for $30 \mathrm{~min}$ at room temperature, washed, and anti-mouse secondary antibody (1:10,000 dilution) for another $30 \mathrm{~min}$ at room temperature.

To determine the effect of PKC inhibition on JNK phosphorylation, $\mathrm{MCF}-7 / \mathrm{COX}-2$ cells were plated at $4 \times 10^{5}$ cells $/$ well in 6-well plates in DMEM/F-12 medium containing 5\% FBS.
Two days later, cells were treated with the PKC inhibitor Gö6976 (0, 25 and $50 \mathrm{nM})$ for $8 \mathrm{~h}$. Untreated and treated cells were harvested and lysed. Western blot analysis was performed as described above.

Extraction ofnuclearproteins. Nuclearproteins were extracted as previously described (23). MCF-7 and MCF-7/COX-2 cells were plated at $4 \times 10^{5}$ cells/well in 6 -well plates in DMEM/ F-12 medium containing 5\% FBS. Cells were harvested, and cell pellets were lysed with $250 \mu \mathrm{l}$ buffer (10 mM HEPES, $10 \mathrm{mM} \mathrm{KCl}, 0.5 \%$ Nonidet P-40, pH 7.9) on ice for $15 \mathrm{~min}$. Nuclei were pelleted by centrifugation at $13,000 \mathrm{rpm}$ for $1 \mathrm{~min}$, and nuclear proteins were extracted with $50 \mu 1$ nuclear extraction buffer (20 mM HEPES, $400 \mathrm{mM} \mathrm{NaCl}$, pH 7.9). Nuclear protein concentrations were determined using the Bio-Rad DC protein assay. Nuclear proteins $(50 \mu \mathrm{g})$ were electrophoresed on $12 \%$ polyacrylamide gels (Bio-Rad Laboratories), transferred to nitrocellulose membranes (BioRad Laboratories), and western blot analysis for c-Jun was performed (primary antibody was added at a 1:500 dilution). Histone H3 was used as a loading control. Membranes were incubated with the anti-Histone $\mathrm{H} 3$ antibody (1:5,000 dilution) for $30 \mathrm{~min}$ at room temperature, washed, and with the anti-mouse secondary antibody (1:5,000 dilution) for another $30 \mathrm{~min}$ at room temperature.

Matrigel invasion assay. Matrigel invasion assay was preformed as previously described $(13,23,24)$ by counting the number of cells that invaded through Transwell inserts coated with the Matrigel artificial basement membrane. Six-well plate Transwell inserts with $8-\mu \mathrm{m}$ pore-size polycarbonate filters (Thermo Fisher Scientific, Middleton, VA, USA) were coated with Matrigel $(0.7 \mathrm{mg} / \mathrm{ml})$ and placed at room temperature for $40 \mathrm{~min}$. MCF-7/COX-2 cells $\left(4 \times 10^{5}\right.$ in $\left.500 \mu \mathrm{l}\right)$ were pretreated with the JNK inhibitor SP600125 or the ERK inhibitor PD98059 $(0,5$ or $10 \mu \mathrm{M})$ in DMEM/F-12 medium containing $5 \%$ FBS for $30 \mathrm{~min}$ before being added to the Matrigel-coated Transwell inserts. Seventy-two hours later, cells that invaded through the Matrigel onto the lower side of the filter were fixed, stained with Hema-3 and photographed. The invaded cells from each filter were counted in five fields under a light microscope at magnification $\mathrm{x} 40$. The invasiveness of MCF-7/ COX-2 cells was expressed as the mean number of cells that had invaded to the lower side of the filter. The experiments were performed in triplicate wells.

CellTiter 96 Aqueous non-radioactive proliferation assay. The inhibitory effects of tamoxifen on MCF-7/COX-2 cells were studied as previously described (10). MCF-7/COX-2 cells were plated at 1,000 cells/well in 96-well plates in $0.1 \mathrm{ml}$ of DMEM/F-12 medium supplemented with 5\% FBS. The next day, the medium was replaced with DMEM/F-12 medium supplemented with 5\% charcoal-stripped serum (CSS). Twenty-four hours later, cells were pretreated with SP600125 $(0,5$ and $10 \mu \mathrm{M})$ before being treated with various concentrations of tamoxifen for 5 days. At the end of the incubation, cell proliferation was determined by the Promega (Madison, WI, USA) CellTiter 96 Aqueous non-radioactive proliferation (MTS) assay and was expressed as the percentage of proliferating cells relative to the untreated cells. 

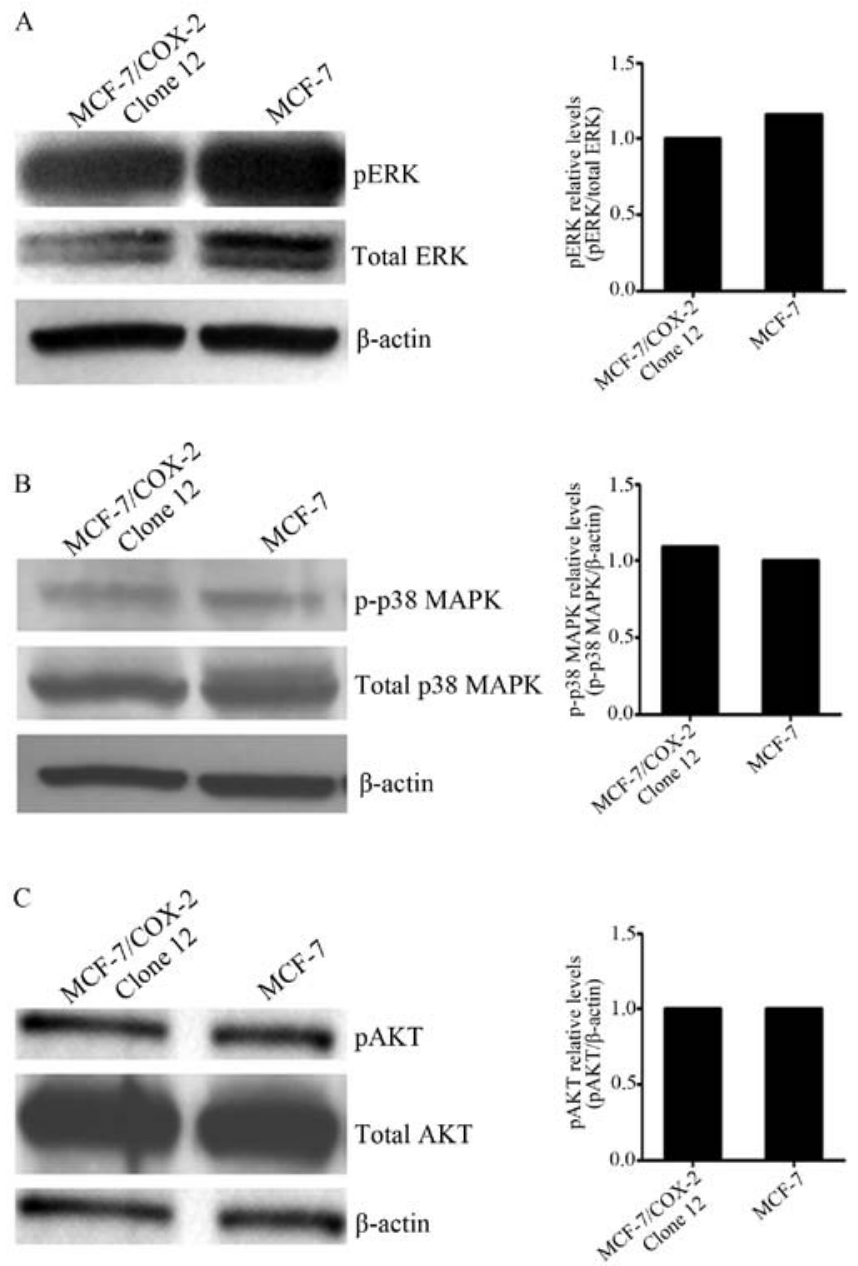

Figure 1. COX-2 does not enhance ERK, p38 MAPK or Akt phosphorylation in MCF-7 cells. COX-2 overexpression did not increase (A) ERK, (B) p38 MAPK or (C) Akt phosphorylation.

\section{Results}

COX-2 overexpression increases phosphorylated JNK levels and nuclear c-Jun levels. High levels of COX-2 or $\mathrm{PGE}_{2}$, have been associated with activation of MAPKs (19-21) and Akt (22). We sought to determine whether MAPK and/or Akt are utilized by COX-2 to induce breast cancer cell invasion and tamoxifen resistance. First, we determined whether COX-2 overexpression alters the phosphorylation levels of the MAPK family or that of Akt. Phosphorylation levels of ERK (Fig. 1A), p38 MAPK (Fig. 1B) and Akt (Fig. 1C) were very similar between the MCF-7/COX-2 and MCF-7 parental cells. However, higher JNK phosphorylation levels were observed in $\mathrm{MCF}-7 / \mathrm{COX}-2$ cells when compared with levels in the MCF-7 cells (Fig. 2A). This corresponded to higher nuclear c-Jun levels in MCF-7/COX-2 cells than levels in MCF-7 cells (Fig. 2B). Previously we showed that PKC plays an essential role in mediating $\mathrm{COX}$-2-induced invasion and tamoxifen resistance in MCF-7 breast cancer cells (10). To determine whether JNK is downstream of PKC in the COX-2 pathway, we treated MCF-7/COX-2 cells with the PKC inhibitor Gö6976 and utilized western blotting to analyze JNK phosphorylation levels. Inhibition of PKC resulted in decreased JNK phos-
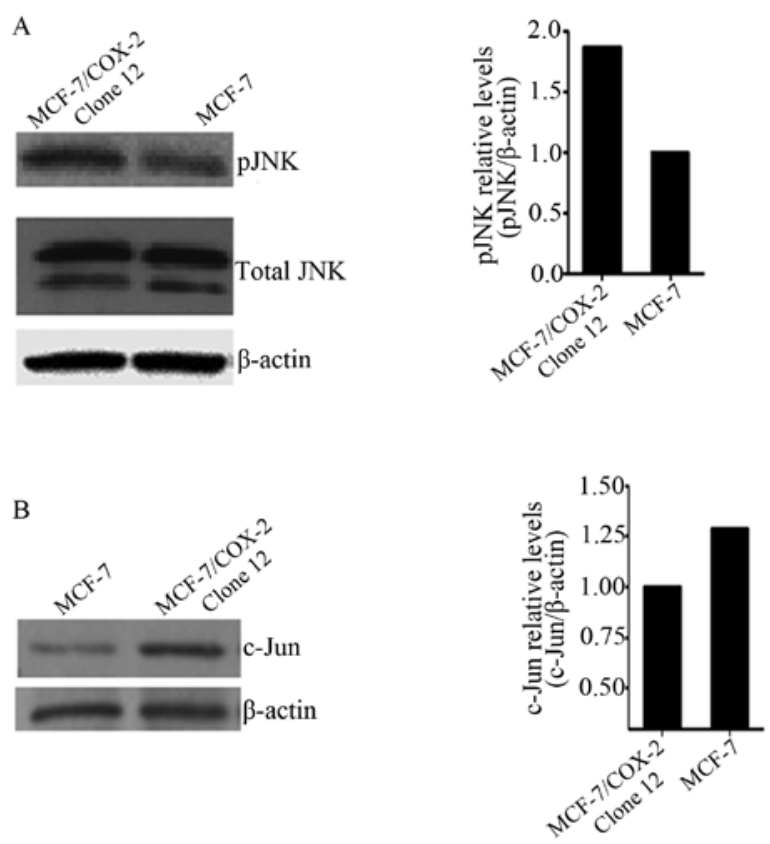

C
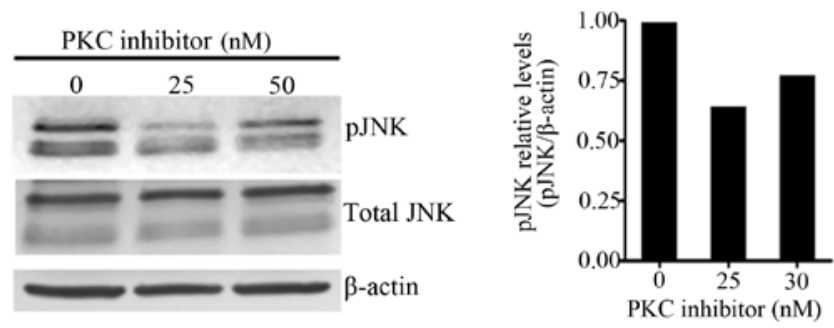

Figure 2. COX-2 utilizes PKC to enhance JNK phosphorylation and nuclear c-Jun levels in MCF-7 cells. (A) JNK phosphorylation and (B) nuclear c-Jun levels were higher in the MCF-7/COX-2 cells when compared with levels in the MCF-7 breast cancer cells. (C) Inhibition of PKC decreased JNK phosphorylation in the MCF-7/COX-2 cells.

phorylation in the MCF-7/COX-2 cells (Fig. 2C). These data indicate that $\mathrm{PKC}$ regulates COX-2-induced JNK activation.

Inhibition of JNKs decreases the invasiveness of MCF-7/COX-2 cells. Since we observed that COX-2 stimulates JNK phosphorylation, we hypothesize that COX-2 utilizes JNKs to induce invasion. MCF-7/COX-2 breast cancer cells were pretreated with SP600125, a chemical inhibitor against JNKs, to determine whether JNK inhibition would decrease COX-2mediated invasion. At 5 and $10 \mu \mathrm{M}$ concentration, SP600125 decreased MCF-7/COX-2 invasive activity by $\sim 75$ and $80 \%$, respectively (Fig. 3A). On the other hand, since COX-2 did not increase ERK phosphorylation, we did not expect ERK to mediate COX-2-induced invasion. Indeed, when we treated MCF-7/COX-2 cells with PD98059, a chemical inhibitor against ERK, PD98059 did not affect MCF-7/COX-2 invasive activity (Fig. 3B). These data indicate that JNKs, not ERK, mediate COX-2-induced breast cancer cell invasion.

Inhibition of JNKs does not affect tamoxifen sensitivity in $M C F-7 / C O X-2$ cells. We determined whether JNKs are also essential for COX-2 to induce tamoxifen resistance. As shown 

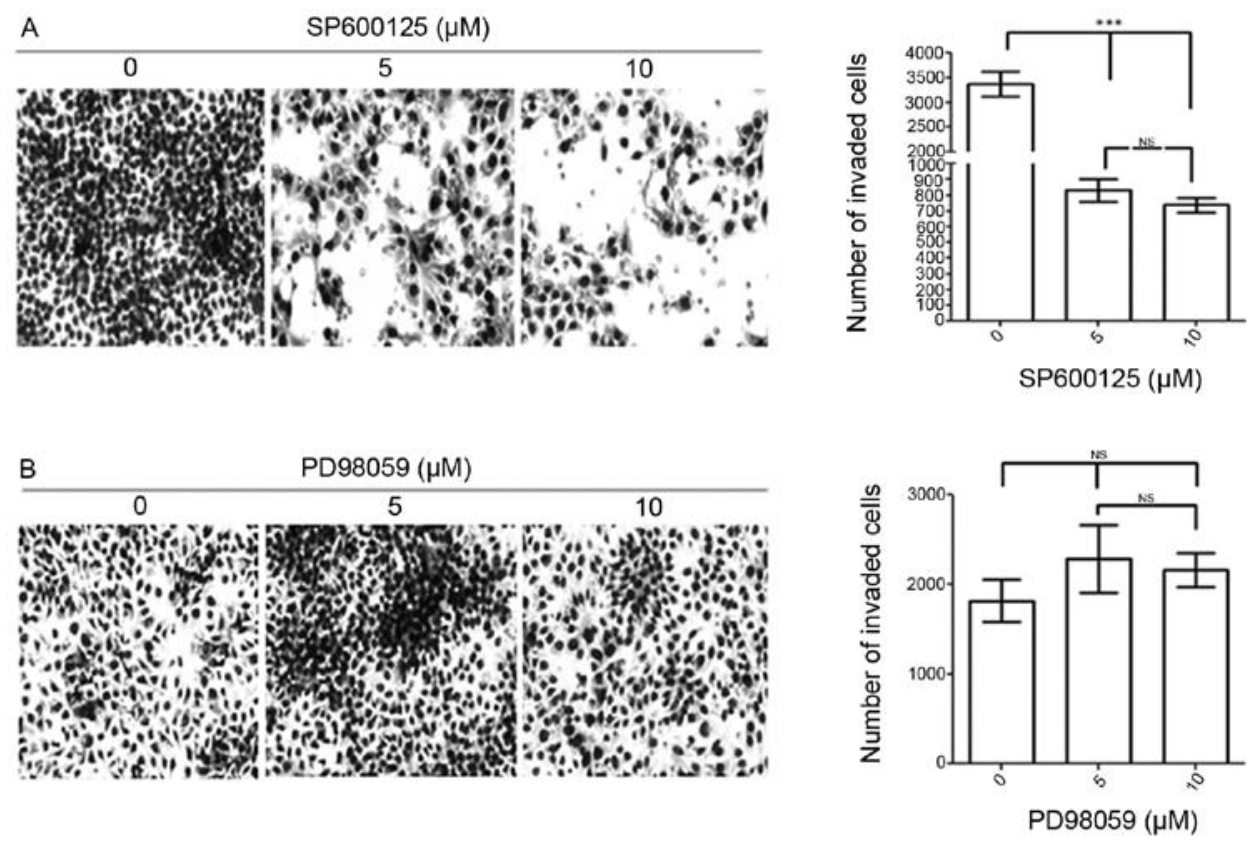

Figure 3. Inhibition aimed at JNK, but not ERK, decreases the invasion of MCF-7/COX-2 cells. Matrigel invasion assay was used to assess the invasiveness of MCF-7/COX-2 cells treated with (A) a JNK inhibitor or (B) an ERK inhibitor.

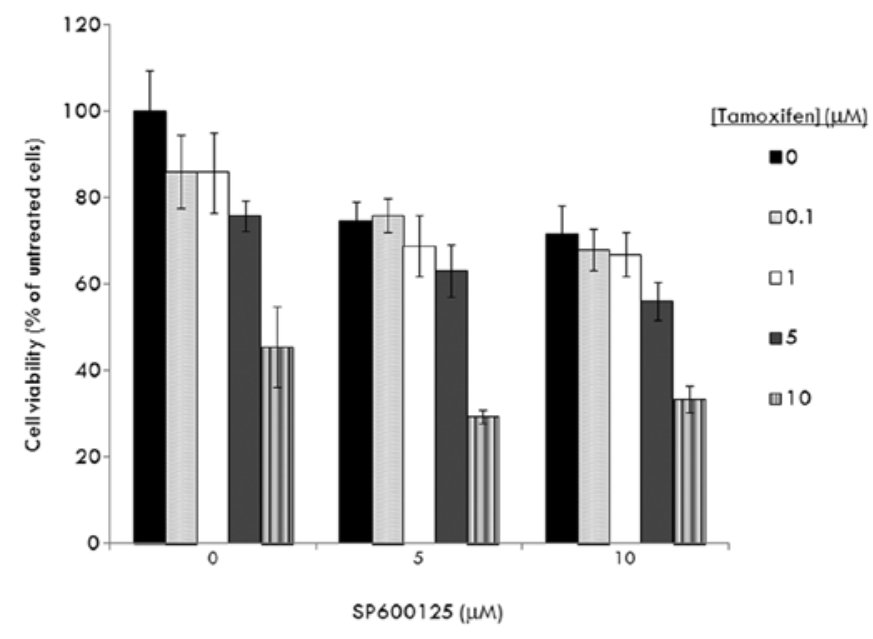

Figure 4. JNK inhibition does not alter the tamoxifen sensitivity of MCF-7/ COX-2 cells. MTS assay was used to evaluate the effect of SP600125 on the sensitivity of MCF-7/COX-2 cells to tamoxifen.

in our previous report (10), MCF-7/COX-2 cells were very insensitive to tamoxifen. At $5 \mu \mathrm{M}$ concentration, tamoxifen inhibited MCF-7/COX-2 cell growth by only $20 \%$ (Fig. 4). In the presence of 5 and $10 \mu \mathrm{M}$ SP600125, tamoxifen (at $5 \mu \mathrm{M}$ ) inhibited MCF-7/COX-2 cell growth by 30 and $40 \%$, respectively ( $\mathrm{P}>0.05)$ (Fig. 4). These data indicate that JNKs do not mediate COX-2-induced tamoxifen resistance.

\section{Discussion}

In the present study, we demonstrated that COX-2 utilizes PKC to stimulate JNK activity, which is essential for COX-2 to induce breast cancer cell invasion. JNKs have been shown to mediate the invasive activity of breast cancer cells induced by various proteins, including interleukin-8 (13), leptin (23) and transglutaminase (25). Activated JNKs can translocate to the nucleus where they regulates transcription factors such as c-Jun, ATF-2, Elk-1, p53 and c-Myc, resulting in enhanced expression and/or activity of proteases, such as urokinase plasminogen activator (13), metalloproteinase-2 (23), or reduced expression of programmed cell death 4 (26), a candidate tumor suppressor gene, thereby enhancing the ability of breast cancer cells to invade through the basement membrane. Wang et al (27) also demonstrated that JNKs mediate epithelial-mesenchymal transition, survival and proliferation of breast cancer cells. These pro-tumorigenic properties of JNKs may explain why elevated levels of phosphorylated JNKs have been correlated with a poorer prognosis in breast cancer patients $(28,29)$.

Tamoxifen is the most widely used drug for breast cancer treatment. Unfortunately, many patients with advanced ER $\alpha$-positive disease fail to respond to tamoxifen, and many responsive patients acquire resistance to tamoxifen, leading to disease progression. Although upregulation of JNK activity, c-Jun phosphorylation and AP-1 DNA binding activity have been found in ER $\alpha$-positive breast tumors with the acquired tamoxifen resistance phenotype $(30,31)$, JNKs have not been shown to mediate tamoxifen resistance. Here, we demonstrated that inhibition of JNKs did not resensitize COX-2-overexpressing breast cancer cells to tamoxifen. Our data suggest that either JNKs are not involved in regulating tamoxifen sensitivity, or that inhibition of JNKs alone is not sufficient to reverse tamoxifen resistance. Indeed several mechanisms, including loss or modification of ER $\alpha$ expression, regulation of signal transduction pathways, altered expression of specific microRNAs, balance of co-regulatory proteins and genetic polymorphisms involved in tamoxifen metabolism, could contribute to the development of tamoxifen resistance (32-34). 
In conclusion, we found that COX-2 increased the activity of JNKs to mediate invasion, but not tamoxifen resistance, in MCF-7 breast cancer cells. In breast cancer, COX-2 expression is a predictor of poor disease-free and overall survival (4-9) and has been implicated as a marker of high metastatic potential $(11,12)$. Pharmacological inhibition aiming at JNKs may have potential therapeutic benefit in patients with ER $\alpha$-positive COX-2-overexpressing breast tumors by reducing tumor invasiveness and metastatic potential.

\section{Acknowledgements}

The present study was supported by the Susan G. Komen Breast Cancer Foundation.

\section{References}

1. Eberhart CE, Coffey RJ, Radhika A, Giardiello FM, Ferrenbach S and DuBois RN: Up-regulation of cyclooxygenase 2 gene expression in human colorectal adenomas and adenocarcinomas. Gastroenterology 107: 1183-1188, 1994.

2. Soslow RA, Dannenberg AJ, Rush D, et al: COX-2 is expressed in human pulmonary, colonic, and mammary tumors. Cancer 89: 2637-2645, 2000.

3. Kirschenbaum A, Liu X, Yao S and Levine AC: The role of cyclooxygenase-2 in prostate cancer. Urology 58: 127-131, 2001.

4. Ristimaki A, Sivula A, Lundin J, et al: Prognostic significance of elevated cyclooxygenase-2 expression in breast cancer. Cancer Res 62: 632-635, 2002.

5. Denkert C, Winzer KJ, Muller BM, et al: Elevated expression of cyclooxygenase-2 is a negative prognostic factor for disease-free survival and overall survival in patients with breast carcinoma. Cancer 97: 2978-2987, 2003.

6. O'Connor JK, Avent J, Lee RJ, Fischbach J and Gaffney DK Cyclooxygenase-2 expression correlates with diminished survival in invasive breast cancer treated with mastectomy and radiotherapy. Int J Radiat Oncol Biol Phys 58: 1034-1040, 2004.

7. Spizzo G, Gastl G, Wolf D, et al: Correlation of COX-2 and Ep-CAM overexpression in human invasive breast cancer and its impact on survival. Br J Cancer 88: 574-578, 2003.

8. Surowiak P, Materna V, Matkowski R, et al: Relationship between the expression of cyclooxygenase 2 and MDR1/P-glycoprotein in invasive breast cancers and their prognostic significance. Breast Cancer Res 7: R862-R870, 2005.

9. Holmes MD, Chen WY, Schnitt SJ, et al: COX-2 expression predicts worse breast cancer prognosis and does not modify the association with aspirin. Breast Cancer Res Treat 130: 657-662, 2011.

10. Tari AM, Simeone AM, Li YJ, Gutierrez-Puente Y, Lai S and Symmans WF: Cyclooxygenase-2 protein reduces tamoxifen and $\mathrm{N}$-(4-hydroxyphenyl)retinamide inhibitory effects in breast cancer cells. Lab Invest 85: 1357-1367, 2005.

11. Costa C, Soares R, Reis-Filho J, Leitao D, Amendoeira I and Schmitt F: Cyclo-oxygenase 2 expression is associated with angiogenesis and lymph node metastasis in human breast cancer. J Clin Pathol 55: 429-434, 2002.

12. Ranger GS, Thomas V, Jewell A and Mokbel K: Elevated cyclooxygenase- 2 expression correlates with distant metastases in breast cancer. Anticancer Res 24: 2349-2351, 2004.

13. Simeone AM, Nieves-Alicea R, McMurtry VC, Colella S, Krahe R and Tari AM: Cyclooxygenase-2 uses the protein kinase C/interleukin-8/urokinase-type plasminogen activator pathway to increase the invasiveness of breast cancer cells. Int J Oncol 30: 785-792, 2007.

14. Prosperi JR, Mallery SR, Kigerl KA, Erfurt AA and Robertson FM: Invasive and angiogenic phenotype of MCF-7 human breast tumor cells expressing human cyclooxygenase-2. Prostaglandins Other Lipid Mediat 73: 249-264, 2004.

15. Singh B, Berry JA, Shoher A, Ramakrishnan V and Lucci A: COX-2 overexpression increases motility and invasion of breast cancer cells. Int J Oncol 26: 1393-1399, 2005.
16. Connolly EM, Harmey JH, O'Grady T, et al: Cyclo-oxygenase inhibition reduces tumour growth and metastasis in an orthotopic model of breast cancer. Br J Cancer 87: 231-237, 2002.

17. Kundu N and Fulton AM: Selective cyclooxygenase (COX)-1 or COX-2 inhibitors control metastatic disease in a murine model of breast cancer. Cancer Res 62: 2343-2346, 2002.

18. Roche-Nagle G, Connolly EM, Eng M, Bouchier-Hayes DJ and Harmey JH: Antimetastatic activity of a cyclooxygenase-2 inhibitor. Br J Cancer 91: 359-365, 2004.

19. Ogunwobi O, Mutungi G and Beales IL: Leptin stimulates proliferation and inhibits apoptosis in Barrett's esophageal adenocarcinoma cells by cyclooxygenase-2-dependent, prostaglandin-E2-mediated transactivation of the epidermal growth factor receptor and c-Jun $\mathrm{NH}_{2}$-terminal kinase activation. Endocrinology 147: 4505-4516, 2006.

20. Leone V, di Palma A, Ricchi P, et al: $\mathrm{PGE}_{2}$ inhibits apoptosis in human adenocarcinoma Caco-2 cell line through Ras-PI3K association and cAMP-dependent kinase A activation. Am J Physiol Gastrointest Liver Physiol 293: G673-G681, 2007.

21. Repasky GA, Zhou Y, Morita S and Der CJ: Ras-mediated intestinal epithelial cell transformation requires cyclooxygenase2-induced prostaglandin $\mathrm{E}_{2}$ signaling. Mol Carcinog 46: 958-970, 2007.

22. Zhang Z, Lai GH and Sirica AE: Celecoxib-induced apoptosis in rat cholangiocarcinoma cells mediated by Akt inactivation and Bax translocation. Hepatology 39: 1028-1037, 2004.

23. McMurtry V, Simeone AM, Nieves-Alicea R and Tari AM: Leptin utilizes Jun $\mathrm{N}$-terminal kinases to stimulate the invasion of MCF-7 breast cancer cells. Clin Exp Metastasis 26: 197-204, 2008.

24. Gonzalez-Villasana V, Nieves-Alicea R, McMurtry V, Gutierrez-Puente Y and Tari AM: Programmed cell death 4 inhibits leptin-induced breast cancer cell invasion. Oncol Rep 27: 861-866, 2012.

25. Li Z, Xu X, Bai L, Chen W and Lin Y: Epidermal growth factor receptor-mediated tissue transglutaminase overexpression couples acquired tumor necrosis factor-related apoptosis-inducing ligand resistance and migration through c-FLIP and MMP-9 proteins in lung cancer cells. J Biol Chem 286: 21164-21172, 2011

26. Nieves-Alicea R, Colburn NH, Simeone AM and Tari AM: Programmed cell death 4 inhibits breast cancer cell invasion by increasing tissue inhibitor of metalloproteinases- 2 expression. Breast Cancer Res Treat 114: 203-209, 2008.

27. Wang J, Kuiatse I, Lee AV, Pan J, Giuliano A and Cui X: Sustained c-Jun- $\mathrm{NH}_{2}$-kinase activity promotes epithelial-mesenchymal transition, invasion, and survival of breast cancer cells by regulating extracellular signal-regulated kinase activation. Mol Cancer Res 8: 266-277, 2010.

28. Davidson B, Konstantinovsky S, Kleinberg L, et al: The mitogenactivated protein kinases (MAPK) p38 and JNK are markers of tumor progression in breast carcinoma. Gynecol Oncol 102: 453-461, 2006.

29. Yeh YT, Hou MF, Chung YF, et al: Decreased expression of phosphorylated JNK in breast infiltrating ductal carcinoma is associated with a better overall survival. Int J Cancer 118: 2678-2684, 2006.

30. Johnston SR, Lu B, Scott GK, et al: Increased activator protein-1 DNA binding and c-Jun $\mathrm{NH}_{2}$-terminal kinase activity in human breast tumors with acquired tamoxifen resistance. Clin Cancer Res 5: 251-256, 1999.

31. Schiff R, Reddy P, Ahotupa M, et al: Oxidative stress and AP-1 activity in tamoxifen-resistant breast tumors in vivo. J Natl Cancer Inst 92: 1926-1934, 2000.

32. Garcia-Becerra R, Santos N, Diaz L and Camacho J: Mechanisms of resistance to endocrine therapy in breast cancer: focus on signaling pathways, miRNAs and genetically based resistance. Int J Mol Sci 14: 108-145, 2012.

33. Sweeney EE, McDaniel RE, Maximov PY, Fan P and Jordan VC: Models and mechanisms of acquired antihormone resistance in breast cancer: significant clinical progress despite limitations. Horm Mol Biol Clin Investig 9: 143-163, 2012.

34. Bianco S and Gevry N: Endocrine resistance in breast cancer: from cellular signaling pathways to epigenetic mechanisms. Transcription 3: 165-170, 2012. 